\title{
Activity Factors of the Korean Exposure Factors Handbook
}

\author{
Jae-Yeon Jang', Soo-Nam Jo', So-Yeon Kim'1', Kyung-Eun Lee', Kyung-Ho Choi ${ }^{2}$, Young-Hee Kim² \\ ${ }^{1}$ Department of Preventive Medicine and Public Health, Ajou University School of Medicine, Suwon, ${ }^{2}$ Graduate School of Public Health, \\ Seoul National University, Seoul, Korea
}

Exposure factors based on the Korean population are required for making appropriate risk assessment. It is expected that handbooks for exposure factors will be applied in many fields, as well as by health department risk assessors. The present article describes the development of an exposure factors handbook that specifically focuses on human activities in situations involving the possible risk of exposure to environmental contaminants. We define majour exposure factors that represent behavioral patterns for risk assessment, including time spent on routine activities, in different places, on using transportation, and engaged in activities related to water contact including swimming, bathing and washing. Duration of residence and employment are also defined. National survey data were used to identify recommended levels of exposure factors in terms of time spent on routine activities and period of residence and employment. An online survey was conducted with 2073 subjects who were selected using a stratified random sampling method in order to develop a list of exposure factors for the time spent in different places and in performing water-related activities. We provide the statistical distribution of the variables, and report reference levels of average exposure based on the reliable data in our exposure factors handbook.

Key words: Risk assessment, Handbooks, Environmental exposure

\section{INTRODUCTION}

Exposure to contaminants varies according to the frequency and time of exposure in addition to the concentration of the contaminant. Activity exposure factors, therefore, play an essential role in identifying the exposure dose in a population. The frequency and time of exposure depend on the activity patterns of individuals and the time they spend in the activity environment [1]. In exposure evaluations of contaminants in

Received: September 2, 2013; Accepted: December 17, 2013

Corresponding author: Jae-Yeon Jang, PhD

206 World cup-ro, Yeongtong-gu, Suwon 443-721, Korea

Tel: +82-31-219-5293, Fax: +82-31-219-5084

E-mail: free5293@gmail.com

This is an Open Access article distributed under the terms of the Creative Commons Attribution Non-Commercial License (http://creativecommons.org/licenses/bync/3.0/) which permits unrestricted non-commercial use, distribution, and reproduction in any medium, provided the original work is properly cited. large populations, an indirect approach applying mathematical models is typically used, as an actual measurement is often technologically and financially unfeasible [2-4]. Data on the activity patterns of the subject population are essential for conducting an indirect evaluation based on such models [4]. These data on activity patterns include what activities are closely related to the exposure being studied, as well as information about the time required to carry out an activity, and places where the activity is performed [5-7]. Since activity patterns vary by age, residential area, and occupation, it is necessary to examine differences in terms of demographic characteristics to reduce the uncertainty of an exposure assessment $[4,8,9]$. The major variables related to the activity patterns for exposure assessment include the time required for each activity, the time spent on routine activities, places, transportation and duration of contact with water, such as washing the face, showering, bathing, and swimming, as well as occupational and population mobility. Even when the residential environ- 
ment is the same, exposure to contaminants can vary according to the ratio between indoor and outdoor activities. When individuals use any means of transportation, their exposure to contaminants emitted from that mode of transportation and the roads increases. Thus, information about the time they spend in proximity to that mode of transportation and location would be important for assessing exposure.

People engage in activities during which their skin makes contact with contaminants in water during daily life; examples include face and hand washing, showering, bathing, and swimming. Contaminants in the water are absorbed into the body through the skin during such activities, or through evaporation and inhalation. Thus, in exposure assessment, it is important to assess the exposure patterns and duration of contact with water, depending on the specific contaminant in question.

Population mobility refers to the average period of residency between the time a person moves into a house located in a certain area and the time he or she moves out. The average period of residency can serve as the average duration of exposure to contaminants among people in a certain area. Occupational mobility refers to the period of continuous employment at an establishment, and thus can serve as the duration of exposure to contaminants at that establishment.

The purpose of this review is to provide an account of the research-based processes underlying the 2007 project to develop the Korean Exposure Factors Handbook. The review describes the steps taken to determine the most accurate method of calculating the recommended (or reference) levels of exposure factors for Koreans. Levels of exposure factors are examined in relation to the time respondents spent in certain activities. The specific exposure factors and the recommended (or reference) levels calculated for Koreans reviewed herein were as follows: 1) duration required for each activity, time spent on routine activities, in different places, and in using transportation; 2) duration of contact with water (i.e., washing the face, showering, bathing, and swimming); and 3) occupational and population mobility.

\section{DEVELOPMENT PROCESS}

\section{Time Spent on Routine Activities}

This study recategorized and reanalyzed data collected from 27081 adults aged 18 and older as part of the 2004 Time Use Survey. This survey was conducted by this survey was conducted by the Korean National Statistical Office to calculate people's time spent on various activities. The National Statistical Office sampled people ages 10 and older who resided in the nation during the Time Use Survey. The respondents entered information about their activities for 24 hours every 10 minutes [10]. The activities were divided into 167 types, which were classified into nine major categories with 50 subcategories. They were then reclassified into 65 subcategories and 11 categories by referring to the categories of the US Environmental Protection Agency (EPA) Exposure Factors Handbook for use in the exposure assessment to enable international comparisons. Residential area, educational level, and income level were also reclassified. Population weights were assigned according to the reclassified categories of activities to obtain overall statistics on the entire population and the populations involved in each activity. We obtained descriptive statistics on the 65 subcategories of the time spent on activities, including means, standard deviations, maximums, and minimums for continuous variables, and percentages for categorical variables (gender, age, area, day, educational level, and income level).

The time spent on activities was described as reference data rather than recommended values considering their relative applicability. Reference data can be helpful to interpret the mechanism of exposure, but limited to apply directly into calculation process. The US EPA also regards these factors as reference levels. Given the limited space of the study, we present statistics only on time spent on the activities in the 11 categories.

\section{Time Spent in Certain Locations}

The subjects were randomly sampled after designing a sample proportional to the population of 16 metropolitan cities across the nation, stratified by gender and age as of the autumn of 2007. Diaries were distributed to participants who volunteered to participate in advance so that they could record their time spent in various places every 10 minutes between 6:00 in the morning and 6:00 in the morning the next day. They wrote down their places of activity and how much time they spent in each throughout their 24-hour routine, after which they entered the records into a web-based survey, which was designed to avoid repetition and overlapping of answers [11].

The survey took place in the spring (March 21) and summer (July 4) of 2007 to reflect seasonal factors. The final number of participants was 2073 with 1001 in the spring survey and 1072 in the summer survey. After excluding the answers of 67 spring and 27 summer participants (who had clearly not recorded accurate information or had not responded to follow-up calls), 
data from 1980 respondents were used in the final analysis.

Locations were classified into the categories of indoor, outdoor, and transportation. Indoor locations were then further subdivided into home and locations outside of the home. Outdoor locations were subdivided into home, locations outside of the home, and movement, as well as various sub-subcategories for each of these three subcategories. Transportation was classified into the subcategories of bus, taxi, subway, passenger car, truck, high-speed train, and airplane. There were total of 48 sub-subcategories of locations (Supplemental Table 1).

\section{Washing Hands, Washing the Face, Showering, Bathing, and Swimming}

The subjects and procedure for evaluating exposure factors related to face and hand washing, showering, bathing, and swimming were the same as those in evaluating the exposure factors related to the time spent in certain locations. Participants were asked to record their activities along with the time spent in each location in their notebooks.

The exposure time for high-frequency activities, such as hand/face washing and showering, were calculated by daily frequency and duration. Bathing was assessed weekly, and swimming monthly. The items were designed to have the participants write down the frequency and duration of hand and face washing, showering, bathing, and swimming for a given period [11]. The frequency of those activities performed for a day, week, or month, respectively, was multiplied by the duration of each activity to calculate the total time.

\section{Population and Occupational Mobility}

Population mobility was measured by calculating the average period of residency of a sample of $5 \%$ of the data from the 2005 Population and Housing Census [12]. Conducted every five years, the census provides information about the overall characteristics of the population, such as its size, distribution, structure, and housing. The census also provides basic data useful for the development of policy plans and offers sampling frames for all types of surveys on households. Population mobility survey had data on 791188 households and 2227960 people on the 2005 census. The period of residence was a categorical rather than a continuous variable. In an effort to offer strict criteria for risk assessment, the highest-level category was represented by 25 years, which was the maximum value within the category and in other categories, the median values were used. Because the period of residency was entered by household, we assumed that all the members of the same household had the same period of residency in order to estimate the distribution of the period of residency by gender and age, and to calculate the factors of population mobility.

Occupational mobility was based on the 2006 Survey Report on Labor Conditions by Employment Type conducted by the Ministry of Labor [13]. It surveyed approximately six million workers at establishments with five employees or more, according to gender, age, marital status, educational background, type of occupation, and years of continuous employment. Years of continuous employment refers to the period from the time when an individual joined a company to either the time the individual left the company, or the date of the survey if he or she was still currently working at that company. Years of continuous employment included apprenticeships and internships, but not suspension from employment. When a person was rehired by the same company after a certain period since termination or retirement, the individual's previous employment was also included in the years of continuous employment. The present study used the average years of continuous employment reported in the survey.

\section{REFERENCE AND RECOMMENDED VALUES}

Table 1 shows the time spent on each activity. On average, respondents spent the greatest amount of time (mean, 653 minutes) in personal maintenance activities, followed by jobrelated earning activities (mean, 224 minutes) and communication activities. Communication activities included, in descending order, watching television, reading a newspaper, and movement-related activities.

Table 2 shows the time spent in each of three places: indoors, outdoors, and in transportation. Of the respondents, 51.2\% were male and $48.4 \%$ were female, and the largest proportion (24.2\%) was aged from 35 to 44, while the most common level of education was university graduates (56.7\%). The general characteristics of the respondents are given in Supplemental Table 2.

On average, the respondents spent approximately 1281 minutes a day indoors, 76.2 minutes outdoors, and $82.8 \mathrm{~min}$ utes in a mode of transportation. Women spent an average of 50.3 more minutes indoors than did men, while men spent an average of 12.5 more minutes outdoors and 37.7 more minutes in transit than their female counterparts did.

Table 3 shows the time spent washing the hands, washing 
Table 1. Reference values for time spent in representative activities (min/d)

\begin{tabular}{|c|c|c|c|c|c|c|c|c|c|c|}
\hline Activities & & $\mathbf{n}$ & Mean (SD) & 5th & 10th & 25th & 50th & 75th & 90th & 95th \\
\hline \multirow[t]{3}{*}{ Income related activities } & Male & 24940 & $286(247.0)$ & 0 & 0 & 0 & 320 & 500 & 600 & 650 \\
\hline & Female & 29222 & 166 (216.9) & 0 & 0 & 0 & 0 & 370 & 510 & 570 \\
\hline & Total & 54162 & $224(239.6)$ & 0 & 0 & 0 & 130 & 450 & 560 & 620 \\
\hline \multirow[t]{3}{*}{ Housework } & Male & 24940 & 19 (42.7) & 0 & 0 & 0 & 0 & 20 & 60 & 100 \\
\hline & Female & 29222 & 140 (103.9) & 0 & 0 & 50 & 130 & 210 & 280 & 320 \\
\hline & Total & 54162 & 82 (100.5) & 0 & 0 & 0 & 30 & 140 & 230 & 290 \\
\hline \multirow[t]{3}{*}{ Child care } & Male & 24940 & $8(30.7)$ & 0 & 0 & 0 & 0 & 0 & 20 & 60 \\
\hline & Female & 29222 & 39 (85.7) & 0 & 0 & 0 & 0 & 30 & 140 & 230 \\
\hline & Total & 54162 & $24(67.0)$ & 0 & 0 & 0 & 0 & 0 & 80 & 160 \\
\hline \multirow{3}{*}{$\begin{array}{l}\text { Product and service } \\
\text { purchasing }\end{array}$} & Male & 24940 & $9(27.5)$ & 0 & 0 & 0 & 0 & 0 & 30 & 60 \\
\hline & Female & 29222 & $25(41.6)$ & 0 & 0 & 0 & 0 & 30 & 80 & 110 \\
\hline & Total & 54162 & $17(36.3)$ & 0 & 0 & 0 & 0 & 20 & 60 & 90 \\
\hline \multirow[t]{3}{*}{ Individual care } & Male & 24940 & 651 (118.1) & 480 & 520 & 580 & 640 & 720 & 800 & 860 \\
\hline & Female & 29222 & 654 (113.2) & 490 & 530 & 580 & 640 & 720 & 800 & 850 \\
\hline & Total & 54162 & 653 (115.6) & 480 & 520 & 580 & 640 & 720 & 800 & 850 \\
\hline \multirow[t]{3}{*}{ Training or education } & Male & 24940 & $31(114.3)$ & 0 & 0 & 0 & 0 & 0 & 20 & 270 \\
\hline & Female & 29222 & 25 (100.9) & 0 & 0 & 0 & 0 & 0 & 0 & 190 \\
\hline & Total & 54162 & $28(107.7)$ & 0 & 0 & 0 & 0 & 0 & 0 & 230 \\
\hline \multirow[t]{3}{*}{ Organization activities ${ }^{1}$} & Male & 24940 & 14 (57.3) & 0 & 0 & 0 & 0 & 0 & 0 & 100 \\
\hline & Female & 29222 & $20(65.0)$ & 0 & 0 & 0 & 0 & 0 & 70 & 150 \\
\hline & Total & 54162 & 17 (61.4) & 0 & 0 & 0 & 0 & 0 & 40 & 130 \\
\hline \multirow{3}{*}{$\begin{array}{l}\text { Entertainment/social } \\
\text { activities }^{2}\end{array}$} & Male & 24940 & $61(77.2)$ & 0 & 0 & 0 & 30 & 90 & 170 & 220 \\
\hline & Female & 29222 & $64(73.6)$ & 0 & 0 & 10 & 40 & 90 & 160 & 210 \\
\hline & Total & 54162 & $63(75.4)$ & 0 & 0 & 0 & 40 & 90 & 160 & 220 \\
\hline \multirow[t]{3}{*}{ Leisure/leisure activities $^{3}$} & Male & 24940 & $74(100.9)$ & 0 & 0 & 0 & 40 & 110 & 210 & 280 \\
\hline & Female & 29222 & $56(77.0)$ & 0 & 0 & 0 & 30 & 90 & 160 & 210 \\
\hline & Total & 54162 & 65 (89.8) & 0 & 0 & 0 & 30 & 100 & 180 & 250 \\
\hline \multirow[t]{3}{*}{ Communication activities ${ }^{4}$} & Male & 24940 & $172(140.5)$ & 0 & 20 & 70 & 140 & 240 & 370 & 450 \\
\hline & Female & 29222 & $160(124.7)$ & 0 & 20 & 70 & 140 & 230 & 330 & 400 \\
\hline & Total & 54162 & 166 (132.7) & 0 & 20 & 70 & 140 & 230 & 350 & 430 \\
\hline \multirow[t]{3}{*}{ Moving } & Male & 24940 & $115(89.2)$ & 0 & 20 & 50 & 100 & 160 & 230 & 280 \\
\hline & Female & 29222 & $90(77.7)$ & 0 & 0 & 40 & 70 & 120 & 190 & 230 \\
\hline & Total & 54162 & 102 (84.4) & 0 & 20 & 40 & 80 & 140 & 210 & 260 \\
\hline
\end{tabular}

SD, standard deviation.

${ }^{1}$ Participation in civil advocacy group, volunteer works and religious activities.

${ }^{2}$ Individual or inter personal activities for social relationship such as participating in official or non-official ceremonies, seeing movies, plays or museum and visiting neighbors or relatives.

${ }^{3}$ Individual activities spending time for relax and enjoying.

${ }^{4}$ Defined as spending time in communicating with social environment thorough non-living media like newspaper, radio, TV and so on.

the face, showering, bathing, and swimming. Respondents washed their hands a mean of 7.4 times a day; women recorded a mean of 8.6 times and men a mean of 6.2 times.

Total spending hours in a day were not presented in this paper but easily calculated by multiplying each value of times/d by minutes/event. On a daily basis, respondents spent $9.6 \mathrm{~min}$ utes and 16.8 minutes washing their faces and showering, re- spectively; in addition, women spent more time than did men in washing their faces (10.71 vs. 8.6 minutes) and in showering (18.3 vs. 15.4 minutes). On a weekly basis, respondents spent a mean of 23.2 minutes in the shower, and women spent slightly more time than did men ( 23.9 vs. 22.5 minutes). Finally, respondents spent an average of 20.7 minutes swimming on a monthly basis, with women spending more time swimming 
Table 2. Time spent in certain locations including indoors, outdoors, and vehicles ( $\mathrm{min} / \mathrm{d})$

\begin{tabular}{llcccccccc}
\hline \multicolumn{1}{l}{ Time spent in a place } & $\mathbf{n}$ & Mean (SD) & 5th & 25th & 50th & 75th & 90th & 95th \\
\hline Indoors & Male & 1013 & $1256.4(136.5)$ & 1010 & 1210 & 1290 & 1350 & 1390 & 1410 \\
& Female & 967 & $1306.7(106.5)$ & 1140 & 1260 & 1320 & 1380 & 1420 & 1440 \\
& Total & 1980 & $1281(125.3)$ & 1065 & 1230 & 1310 & 1360 & 1400 & 1440 \\
\multirow{2}{*}{ Outdoors } & Male & 1013 & $82.3(110.4)$ & 0 & 10 & 50 & 110 & 200 & 290 \\
& Female & 967 & $69.8(89.5)$ & 0 & 10 & 50 & 100 & 170 & 220 \\
& Total & 1980 & $76.2(100.9)$ & 0 & 10 & 50 & 100 & 180 & 245 \\
\multirow{6}{*}{ Vehicles } & Male & 1013 & $101.2(93.4)$ & 0 & 40 & 90 & 140 & 210 & 270 \\
& Female & 967 & $63.5(68.8)$ & 0 & 0 & 50 & 100 & 150 & 180 \\
& Total & 1980 & $82.8(84.4)$ & 0 & 20 & 70 & 120 & 180 & 230 \\
\hline
\end{tabular}

SD, standard deviation.

Table 3. Time spent on specific activities inducing dermal exposure to water including washing hands and face, taking a shower, bathing, and swimming

\begin{tabular}{|c|c|c|c|c|c|c|c|c|c|c|}
\hline \multicolumn{3}{|c|}{ Activities related to dermal exposure to water } & \multirow{2}{*}{$\begin{array}{c}\mathbf{n} \\
1013\end{array}$} & \multirow{2}{*}{$\begin{array}{c}\text { Mean (SD) } \\
6.2(3.7)\end{array}$} & \multirow{2}{*}{$\begin{array}{r}\text { 5th } \\
3\end{array}$} & \multirow{2}{*}{$\begin{array}{c}\text { 25th } \\
4\end{array}$} & \multirow{2}{*}{$\begin{array}{c}\text { 50th } \\
5\end{array}$} & \multirow{2}{*}{$\begin{array}{c}\text { 75th } \\
8\end{array}$} & \multirow{2}{*}{$\begin{array}{c}\text { 90th } \\
10\end{array}$} & \multirow{2}{*}{$\begin{array}{c}\text { 95th } \\
12\end{array}$} \\
\hline Washing hands & Times/d & Male & & & & & & & & \\
\hline & & Female & 967 & $8.6(6.2)$ & 3 & 5 & 7 & 10 & 15 & 20 \\
\hline & & Total & 1980 & $7.4(5.2)$ & 3 & 5 & 6 & 10 & 12 & 16 \\
\hline \multirow[t]{6}{*}{ Washing face } & Times/d & Male & 1013 & $2.2(1.0)$ & 1 & 2 & 2 & 3 & 3 & 4 \\
\hline & & Female & 967 & $2.0(0.9)$ & 1 & 2 & 2 & 2 & 3 & 3 \\
\hline & & Total & 1980 & $2.1(1.0)$ & 1 & 2 & 2 & 2 & 3 & 4 \\
\hline & Minutes/event & Male & 1013 & $4.1(3.8)$ & 1 & 2 & 3 & 5 & 10 & 10 \\
\hline & & Female & 967 & $5.3(4.1)$ & 1 & 3 & 5 & 5 & 10 & 10 \\
\hline & & Total & 1980 & $4.7(4.0)$ & 1 & 2 & 3 & 5 & 10 & 10 \\
\hline \multirow[t]{6}{*}{ Taking a shower } & Times/d & Male & 1013 & $1.0(0.7)$ & 0 & 1 & 1 & 1 & 2 & 2 \\
\hline & & Female & 967 & $1.0(0.8)$ & 0 & 1 & 1 & 1 & 2 & 2 \\
\hline & & Total & 1980 & $1.0(0.7)$ & 0 & 1 & 1 & 1 & 2 & 2 \\
\hline & Minutes/event & Male & 1013 & $15.2(7.4)$ & 5 & 10 & 15 & 20 & 25 & 30 \\
\hline & & Female & 967 & $19.3(8.7)$ & 5 & 15 & 20 & 25 & 30 & 30 \\
\hline & & Total & 1980 & $17.2(8.3)$ & 5 & 10 & 15 & 20 & 30 & 30 \\
\hline \multirow[t]{6}{*}{ Bathing } & Times/wk & Male & 1013 & $1.8(2.8)$ & 0 & 0 & 1 & 2 & 6 & 7 \\
\hline & & Female & 967 & $2.0(2.6)$ & 0 & 0 & 1 & 2 & 6 & 7 \\
\hline & & Total & 1980 & $1.9(2.7)$ & 0 & 0 & 1 & 2 & 6 & 7 \\
\hline & Minutes/event & Male & 1013 & $20.3(14.6)$ & 5 & 10 & 20 & 30 & 40 & 60 \\
\hline & & Female & 967 & $19.3(12.8)$ & 5 & 10 & 20 & 30 & 30 & 40 \\
\hline & & Total & 1980 & $19.8(13.7)$ & 5 & 10 & 20 & 30 & 30 & 50 \\
\hline \multirow[t]{6}{*}{ Swimming } & Times/mo & Male & 1013 & $0.3(1.9)$ & 0 & 0 & 0 & 0 & 0 & 1 \\
\hline & & Female & 967 & $0.5(2.6)$ & 0 & 0 & 0 & 0 & 0 & 1 \\
\hline & & Total & 1980 & $0.4(2.3)$ & 0 & 0 & 0 & 0 & 0 & 1 \\
\hline & Minutes/event & Male & 1013 & $49.4(22.1)$ & 10 & 30 & 50 & 60 & 90 & 90 \\
\hline & & Female & 967 & $53.5(15.8)$ & 30 & 47.5 & 50 & 60 & 80 & 80 \\
\hline & & Total & 1980 & 51.3 (19.5) & 20 & 36 & 50 & 60 & 80 & 90 \\
\hline
\end{tabular}

SD, standard deviation.

than did men (24.9 vs. 16.7 minutes).

Table 4 presents data on population mobility in the form of the average period of residency. Koreans recorded an average of 8.8 years of residency (median, 7.5 years). On average, the period of residency was the shortest in Seoul (mean, 5.3 years) (Supplemental Table 3). The metropolitan cities recorded a 
Table 4. Average residency period as a factor of population mobility based on gender and age group (y)

\begin{tabular}{|c|c|c|c|c|c|c|c|c|}
\hline & & $\mathrm{n}$ & Mean & 25th & 50th & 75th & 90th & 95th \\
\hline \multirow[t]{2}{*}{ Gender } & Male & 18757803 & 8.6 & 2.5 & 7.5 & 15 & 25 & 25 \\
\hline & Female & 19297503 & 8.9 & 2.5 & 7.5 & 15 & 25 & 25 \\
\hline \multirow[t]{11}{*}{ Age } & $15-24$ & 6762646 & 7.3 & 2.5 & 2.5 & 15 & 15 & 25 \\
\hline & $25-29$ & 3671847 & 6.4 & 2.5 & 2.5 & 7.5 & 15 & 25 \\
\hline & $30-34$ & 4096282 & 5.1 & 2.5 & 2.5 & 7.5 & 15 & 25 \\
\hline & $35-39$ & 4112785 & 5.4 & 2.5 & 2.5 & 7.5 & 15 & 25 \\
\hline & $40-44$ & 4123041 & 6.6 & 2.5 & 2.5 & 7.5 & 15 & 25 \\
\hline & $45-49$ & 3900899 & 8.1 & 2.5 & 7.5 & 15 & 15 & 25 \\
\hline & $50-54$ & 2855297 & 9.8 & 2.5 & 7.5 & 15 & 25 & 25 \\
\hline & $55-59$ & 2278438 & 11.6 & 2.5 & 7.5 & 15 & 25 & 25 \\
\hline & $60-64$ & 1888853 & 13.4 & 2.5 & 15 & 25 & 25 & 25 \\
\hline & $65-69$ & 1680067 & 15.1 & 7.5 & 15 & 25 & 25 & 25 \\
\hline & $\geq 70$ & 2685151 & 15.9 & 7.5 & 15 & 25 & 25 & 25 \\
\hline Total & & 38055306 & 8.8 & 7.5 & 15 & 25 & 25 & 25 \\
\hline
\end{tabular}

Table 5. Average Length of survey in each type of occupation in 2006 (y)

\begin{tabular}{|c|c|c|c|c|}
\hline Classification & n & $\begin{array}{c}\text { Male } \\
(n=4644 \text { 026) }\end{array}$ & $\begin{array}{c}\text { Female } \\
(n=2106170)\end{array}$ & Total \\
\hline Managers & 303605 & 10.3 & 6.8 & 10.0 \\
\hline Professionals & 712592 & 7.9 & 4.5 & 6.5 \\
\hline $\begin{array}{l}\text { Technicians and } \\
\text { associate } \\
\text { professionals }\end{array}$ & 987710 & 6.1 & 3.6 & 5.5 \\
\hline $\begin{array}{l}\text { Clerical support } \\
\text { workers }\end{array}$ & 1881947 & 7.0 & 4.3 & 5.9 \\
\hline Service workers & 235752 & 5.0 & 3.0 & 3.7 \\
\hline $\begin{array}{l}\text { Service and sales } \\
\text { workers }\end{array}$ & 150334 & 4.3 & 2.6 & 3.5 \\
\hline $\begin{array}{l}\text { Skilled agricultural, } \\
\text { forestry, and fishery } \\
\text { workers }\end{array}$ & 10148 & 6.2 & 3.5 & 5.9 \\
\hline $\begin{array}{l}\text { Craft and related } \\
\text { trades workers }\end{array}$ & 587404 & 6.2 & 4.4 & 6.0 \\
\hline $\begin{array}{l}\text { Plant and machine } \\
\text { operators and } \\
\text { assemblers }\end{array}$ & 1374968 & 6.6 & 4.2 & 6.1 \\
\hline $\begin{array}{l}\text { Elementary } \\
\text { occupations }\end{array}$ & 505736 & 3.9 & 3.6 & 3.8 \\
\hline Total & 6750196 & 6.7 & 4.0 & 5.8 \\
\hline
\end{tabular}

Values are presented as arithmetic means.

shorter period of residency than did other areas. Jeollanam Province recorded the longest average period of residency at 13.1 years (median, 15 years).

Table 5 presents data on occupational mobility. Korean workers reported an average of 5.8 years of continuous employment, with male workers (6.7 years) reporting a period about 1.7 times longer than that of their female counterparts (4.0 years). With respect to occupation, high-ranking executives and managers reported the longest average duration of continuous employment at 10.0 years, followed by professionals, at an average of 6.5 years.

\section{CONCLUSION}

This research was conducted using a representative sample of national data to provide information about respondents' duration of certain activities to develop recommended exposure factors. The study investigated time spent in places, transportation, washing the face and hands, showering, bathing, and swimming. Furthermore, we examined variations by season, gender, region, and age. The results of this study are considered reliable because of their representativeness of the national population. However, it is possible that the results of the Development of Korean Exposure Factors Handbook project completed in 2007 does not reflect recent and abrupt changes in activity caused by lifestyle changes. This is because the activity data were generated in 2004 or taken from the national census data in 2005. Therefore, a review of the relevance of the data for future revisions is highly recommended. Although the activity assessment has great potential to capture population patterns, the major categories of activities and their corresponding time requirements are selectively provided in this document. Furthermore, there are differences between the Korean and US EPA classification schemes for activity assessments in both the exposure handbooks for different social and 
cultural behaviors. For example, the US EPA Handbook adopted the classification of the American Time Use Survey, which categorized the self-repair of appliances or automobiles as 'house maintenance,' while purchasing services for appliances or automobiles was categorized as 'purchasing goods or services.' In contrast, the Korean Time Use Survey, reflected in the Korean exposure factors handbook, has no category for 'purchasing goods or services.' However, purchasing activities were separately categorized into work, study, household care, and leisure activities according to the situation. Furthermore, it classified the use of services or the self-repair of an automobile into the 'household care' category.

When the results were compared with those in the US EPA handbook, Koreans spent more time in taking care of children (mean, $24 \mathrm{~min} / \mathrm{d}$ ), individual care (mean, $653 \mathrm{~min} / \mathrm{d}$ ), training or education (mean, $28 \mathrm{~min} / \mathrm{d}$ ), and leisure activities (mean, 65 $\mathrm{min} / \mathrm{d}$ ) than did Americans (mean, 23, 642, 22 and $43 \mathrm{~min} / \mathrm{d}$, respectively) [14]. On the other hand, they spent less time on home management, product and service purchasing, and communication. Koreans spent slightly more time (mean, 21.35 hours) indoors than did Americans (mean, 21.0 hours), and they also spent a little more time on modes of transportation (mean, 82.8 minutes) than Americans (mean, 78 minutes). Koreans also spent 13.766 hours at home, which was less than the 16.4 hours among Americans and the 15.8 hours among Japanese.

Koreans washed their hands an average 7.4 times a day, which was a small increase from the 6.4 times in previous study [15]. The frequency of taking a shower per day among Koreans was the same as the reference level in the US EPA handbook, but they spent more time per shower than did Americans. Furthermore, Americans swam for longer than did Koreans ( 0.4 hours per month). The Japanese Exposure Factors Handbook reports only the time duration for activities. The Japanese spent considerably less time showering and bathing than did Koreans. Although it was not included in the table, those who swam accounted for about $7 \%$ of the entire sample. They spent 292.2 minutes of swimming at a time, and this was longer than the 268.5 minutes reported by Japanese people [16]. With respect to population mobility, the average period of residency among Koreans was 8.8 years, which was about twice the 4.6 years reported by Americans. With regard to occupational mobility, the average years of continuous employment among Koreans was 5.8 years, which was 0.8 years less than the American average of 6.6 years. In particular, Ko- rean women reported an average of 4.0 years of continuous employment, which was shorter by about 1.4 years than the American average of 5.4 years.

\section{CONFLICT OF INTEREST}

The authors have no conflicts of interest with the material presented in this paper.

\section{REFERENCES}

1. Codex Committee on Food Hygiene Codex Alimentarius Commission. Principles and guidelines for the conduct of microbiological risk assessment. Geneva: World Health Organization; 1999, p. 1-4.

2. Burke JM, Zufall MJ, Ozkaynak H. A population exposure model for particulate matter: case study results for PM(2.5) in Philadelphia, PA. J Expo Anal Environ Epidemiol 2001;11(6):470-489.

3. Kousa A, Kukkonen J, Karppinen A, Aarnio P, Koskentalo T. A model for evaluating the population exposure to ambient air pollution in an urban area. Atmos Environ 2002;36(13):21092119.

4. Klepeis NE, Nelson WC, Ott WR, Robinson JP, Tsang AM, Switzer $P$, et al. The National Human Activity Pattern Survey (NHAPS): a resource for assessing exposure to environmental pollutants. J Expo Anal Environ Epidemiol 2001;11(3):231-252.

5. Borrego C, Tchepel O, Costa AM, Martins H, Ferreira J, Miranda Al. Traffic-related particulate air pollution exposure in urban areas. Atmos Environ 2006;40(37):7205-7214.

6 . Hayes SR. Estimating the effect of being indoors on total personal exposure to outdoor air pollution. JAPCA 1989;39(11): 1453-1461.

7. Leech JA, Wilby K, McMullen E, Laporte K. The Canadian Human Activity Pattern Survey: report of methods and population surveyed. Chronic Dis Can 1996;17(3-4):118-123.

8. Blair A, Stewart P, Lubin JH, Forastiere F. Methodological issues regarding confounding and exposure misclassification in epidemiological studies of occupational exposures. Am J Ind Med 2007:50(3):199-207.

9. Fuller GF. Falls in the elderly. Am Fam Physician 2000;61(7): 2159-2168, 2173-2174.

10. Statistics Korea. Time Use Survey 2004 [cited 2013 Aug 8]. Available from: http://meta.narastat.kr/metasvc/svc/SvcMetaDcDtaPopup.do?confmNo=10152\&inputYear=2004 (Korean).

11. Jang JY, Jo SN, Kim SJ, Yoon MJ, Cheong HK, Kim S, et al. De- 
velopment and application of Korean exposure factors. Seoul: Ministry of Environment; 2007, p. 165-224 (Korean).

12. Statistics Korea. Population and Housing Cencus 2005 [cited 2014 Jan 27]. Available from: http://www.census.go.kr/hcensus/ui/html/data/data_060_010.jsp?q_menu $=4 \& q \_s u b=5 \&$ (Korean).

13. Ministry of Labor. Report on Wage Structure Survey 2006. Seoul: Ministry of Labor; 2007, p. 83-97 (Korean).

14. US Environmental Protection Agency. Exposure factors hand- book. Washington, DC: US Environmental Protection Agency; 1997, p. 833-1087.

15. Shin DC, Jang JY, Lee DS, Jeong JH. System development for integrated risk assessment of environmental pollutants. Seoul: Ministry of Environment; 2001, p. 87-108 (Korean).

16. National Institute of Advanced Industrial Science and Technology. Japanese exposure factors handbook summary [cited 2013 Aug 13]. Available from: http://unit.aist.go.jp/riss/crm/ exposurefactors/english_summary.html. 
Supplemental Table 1. Daily time spent in vehicles based on the type of transportation (min)

\begin{tabular}{|c|c|c|c|c|}
\hline \multicolumn{2}{|c|}{ Type of transportation } & \multirow{2}{*}{$\begin{array}{r}\text { Mean } \\
21.5\end{array}$} & \multirow{2}{*}{$\begin{array}{c}\text { 50th } \\
0\end{array}$} & \multirow{2}{*}{$\begin{array}{c}\text { 95th } \\
120\end{array}$} \\
\hline Bus & Female & & & \\
\hline & Male & 18.3 & 0 & 110 \\
\hline & Total & 19.9 & 0 & 120 \\
\hline \multirow[t]{3}{*}{ Taxi } & Female & 1.4 & 0 & 10 \\
\hline & Male & 3.1 & 0 & 20 \\
\hline & Total & 2.2 & 0 & 20 \\
\hline \multirow[t]{3}{*}{ Subway } & Female & 8.8 & 0 & 70 \\
\hline & Male & 16.9 & 0 & 110 \\
\hline & Total & 13 & 0 & 90 \\
\hline \multirow[t]{3}{*}{ Car } & Female & 30.7 & 0 & 150 \\
\hline & Male & 58.4 & 30 & 210 \\
\hline & Total & 44.8 & 0 & 180 \\
\hline \multirow[t]{3}{*}{ Truck } & Female & 1 & 0 & 0 \\
\hline & Male & 3.6 & 0 & 0 \\
\hline & Total & 2.3 & 0 & 0 \\
\hline \multirow[t]{3}{*}{ Train } & Female & 0.1 & 0 & 0 \\
\hline & Male & 0.6 & 0 & 0 \\
\hline & Total & 0.4 & 0 & 0 \\
\hline \multirow[t]{3}{*}{ Airplane } & Female & 0 & 0 & 0 \\
\hline & Male & 0.4 & 0 & 0 \\
\hline & Total & 0.2 & 0 & 0 \\
\hline \multirow[t]{3}{*}{ Total } & Female & 63.5 & 50 & 180 \\
\hline & Male & 101.2 & 90 & 270 \\
\hline & Total & 82.8 & 70 & 230 \\
\hline
\end{tabular}

Supplemental Table 2. Baseline characteristics of participants in the survey of time spent in certain locations

\begin{tabular}{|c|c|c|}
\hline \multicolumn{2}{|l|}{ Characteristics } & \multirow{2}{*}{$\begin{array}{c}\text { Participants } \\
1013(51.2)\end{array}$} \\
\hline Sex & Male & \\
\hline & Female & $967(48.8)$ \\
\hline \multirow[t]{6}{*}{ Age group } & $18-24$ & $270(13.6)$ \\
\hline & $25-34$ & $466(23.5)$ \\
\hline & $35-44$ & $480(24.2)$ \\
\hline & $45-54$ & $435(22)$ \\
\hline & $55-64$ & $285(14.4)$ \\
\hline & $\geq 65$ & $44(2.2)$ \\
\hline \multirow[t]{2}{*}{ Region } & Metropolitan area & $958(48.4)$ \\
\hline & Provinces & $1022(51.6)$ \\
\hline \multirow[t]{4}{*}{ Family income ${ }^{1}$} & $<1000$ & $288(14.5)$ \\
\hline & $1000-2000$ & $318(16.1)$ \\
\hline & $2000-3000$ & $447(22.6)$ \\
\hline & $\geq 3000$ & $927(46.8)$ \\
\hline \multirow[t]{4}{*}{ Education level } & Middle school or less & $74(3.7)$ \\
\hline & High school & $588(29.7)$ \\
\hline & College (2- to 4-year) & $1116(56.4)$ \\
\hline & More than college & $202(10.2)$ \\
\hline Total & & $1980(100.0)$ \\
\hline \multicolumn{3}{|c|}{ Values are presented as number (\%). } \\
\hline
\end{tabular}

\begin{tabular}{lcccccc}
\hline Region & Mean & 25th & 50th & 75th & 90th & 95th \\
\hline Seoul & 5.3 & 2.5 & 2.5 & 7.5 & 15 & 15 \\
Busan & 7.1 & 2.5 & 2.5 & 15 & 15 & 25 \\
Daegu & 6.5 & 2.5 & 2.5 & 7.5 & 15 & 25 \\
Incheon & 6.2 & 2.5 & 2.5 & 7.5 & 15 & 25 \\
Gwangju & 6.8 & 2.5 & 2.5 & 7.5 & 15 & 25 \\
Daejeon & 5.9 & 2.5 & 2.5 & 7.5 & 15 & 25 \\
Ulsan & 6.8 & 2.5 & 2.5 & 15 & 15 & 25 \\
Gyeonggi-do & 5.4 & 2.5 & 2.5 & 7.5 & 15 & 25 \\
Gangwon-do & 9.2 & 2.5 & 7.5 & 15 & 25 & 25 \\
Chungcheongbuk-do & 9.7 & 2.5 & 7.5 & 25 & 25 & 25 \\
Chungcheongnam-do & 10.6 & 2.5 & 7.5 & 25 & 25 & 25 \\
Jeollabuk-do & 11.5 & 2.5 & 15 & 25 & 25 & 25 \\
Jeollanam-do & 13.1 & 7.5 & 15 & 25 & 25 & 25 \\
Gyeongsangbuk-do & 11.2 & 2.5 & 15 & 25 & 25 & 25 \\
Gyeongsangnam-do & 9.8 & 2.5 & 7.5 & 25 & 25 & 25 \\
Jeju-do & 8.9 & 2.5 & 7.5 & 15 & 25 & 25 \\
Total & 8.8 & 2.5 & 7.5 & 15 & 25 & 25 \\
\hline
\end{tabular}

